\title{
Characterization of In Vivo Acquired Resistance of Mycoplasma hyopneumoniae to Macrolides and Lincosamides
}

\author{
TIM STAKENBORG,${ }^{1}$ JO VICCA, ${ }^{2}$ PATRICK BUTAYE, ${ }^{1}$ DOMINIEK MAES,${ }^{2}$ F. CHRIS MINION,${ }^{3}$ \\ JOHAN PEETERS, ${ }^{1}$ AART DE KRUIF, ${ }^{2}$ and FREDDY HAESEBROUCK ${ }^{2}$
}

\begin{abstract}
Macrolides and related antibiotics are used to control mycoplasma infections in the pig industry worldwide. Some porcine mycoplasmas, however, survive these treatments by acquiring resistance. The mechanism of acquired resistance to macrolides and lincosamides was studied in more detail for Mycoplasma hyopneumoniae by comparing both the phenotype and genotype of a resistant field isolate to five susceptible isolates. The MICs were significantly higher for the resistant strain for all antibiotics tested. The MICs for the 16-membered macrolide tylosin ranged from 8 to $16 \mu \mathrm{g}$ for the resistant strain and from 0.03 to $0.125 \mu \mathrm{g} / \mathrm{ml}$ for the five susceptible strains. The MICs for the 15 -membered macrolides and lincosamides were higher than $64 \mu \mathrm{g} / \mathrm{ml}$ for the resistant strain while only 0.06 to $0.5 \mu \mathrm{g} / \mathrm{ml}$ for the susceptible strains. Mycoplasma hyopneumoniae strains are intrinsically resistant to the 14-membered macrolides due to a G2057A transition (E. coli numbering) in their 23S rDNA. Therefore, high MICs were observed for all strains, although the MICs for the resistant strain were clearly increased. An additional, acquired A2058G point mutation was found in the 23S rRNA gene of the resistant strain. No differences linked to resistance were found in the ribosomal proteins $\mathrm{L} 4$ and L22. The present study showed that $23 \mathrm{~S}$ rRNA mutations resulting in resistance to macrolides and lincosamides as described in other Mycoplasma spp. also occur under field conditions in M. hyopneumoniae.
\end{abstract}

\section{INTRODUCTION}

$\mathbf{M}$ YCOPLASMAS ARE THE SMALLEST FREE-LIVING ORGANISMS, carrying no cell wall. As a consequence, they are naturally resistant to antibiotics interfering with cell wall synthesis. Additionally, a number of reports indicate a decrease in susceptibility of mycoplasmas against widely used antimicrobial agents, including the macrolides, lincosamides, and streptogramins (MLS). 2,12,15,25,35,37 MLS antibiotics have overlapping binding sites on the $23 \mathrm{~S}$ rRNA and, hence, related antimicrobial activities. By binding to domain $\mathrm{V}$ of the $23 \mathrm{~S}$ rRNA, they inhibit protein synthesis by means of blocking the path through which nascent peptides exit the ribosome. ${ }^{28,33}$ Additional studies have mapped the recognition site of the 14-membered macrolide erythromycin and its derived ketolides to domain II and IV of the 23S rRNA as well. ${ }^{4,29,36}$

Bacterial species containing only one or two copies of rRNA genes, like all Mycoplasma species, tend to use muta- tions at bases 2,057-2,059 of the 23S rRNA as a way of acquiring resistance. ${ }^{12,16}$ Some mycoplasmas, like $M$. hyopneumoniae, are intrinsically resistant to 14-membered macrolides due to a G2057A transition in their 23S rDNA. ${ }^{12,20,30}$ Additional resistance to MLS antibiotics due to mutations at positions 2,609-2,611 has been observed for several bacterial species. ${ }^{6,14,25}$ A mutation at position 2,062 was linked to resistance against josamycin, a 16-membered macrolide, in an in vitro-selected Mycoplasma hominis strain. ${ }^{11,16}$ For a number of other bacteria, mutations in the L4 and L22 binding proteins were linked to MLS resistance. ${ }^{6,8,9,19,26,27,29,31}$ Nonetheless, acquired resistance to MLS in Mycoplasma species is rarely documented or is induced in vitro rather than observed in field isolates.

The aim of this study was to characterize fully both phenotypically and genetically the in vivo acquired resistance to macrolides and lincosamides in a $M$. hyopneumoniae field isolate.

\footnotetext{
${ }^{1}$ Veterinary and Agrochemical Research Centre, Brussels, Belgium.

${ }^{2}$ Faculty of Veterinary Medicine, Ghent University, Merelbeke, Belgium.

${ }^{3}$ Department of Veterinary Microbiology and Preventive Medicine, Iowa State University, Ames, IA.
} 
Table 1. Selected Primers Used for the Amplification and Sequencing of the 23S, L4, and L22 Genes of the $M$. hyopneumoniae J Reference and Field Strains

\begin{tabular}{llc}
\hline Primer name & \multicolumn{1}{c}{ Primer sequence $\left(5^{\prime} \rightarrow 3^{\prime}\right)$} & \multicolumn{1}{c}{ Number of cycles $(\text { cycle conditions })^{\mathrm{a}}$} \\
\hline L4 FOR & AGCATTCAAAGTCAGAAAAC & $25\left(30 \mathrm{sec}\right.$ at $94^{\circ} \mathrm{C} ; 30 \mathrm{sec}$ at $47.6^{\circ} \mathrm{C} ;$ and $1 \mathrm{~min}$ at $\left.72^{\circ} \mathrm{C}\right)$ \\
L4 REV & GATTCTCTTCTCCAAATTAG & $25\left(30 \mathrm{sec}\right.$ at $94^{\circ} \mathrm{C} ; 30 \mathrm{sec}$ at $52.5^{\circ} \mathrm{C} ;$ and $1 \mathrm{~min}$ at $\left.72^{\circ} \mathrm{C}\right)$ \\
L22 FOR & AGCAGTCGCTTCACTCAAAA & $25\left(30 \mathrm{sec}\right.$ at $94^{\circ} \mathrm{C} ; 30 \mathrm{sec}$ at $55.2^{\circ} \mathrm{C} ;$ and $1 \mathrm{~min}$ at $\left.72^{\circ} \mathrm{C}\right)$ \\
L22 REV & ACCTCTTTTTCTTGCGCTAA \\
23 FOR & GGTAGCGAAATCCTTGTCA & \\
$23 \mathrm{~S}$ REV & GAGCAGCTCTCATCAATATTCC & \\
\hline
\end{tabular}

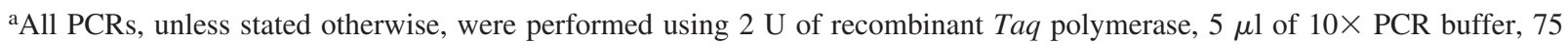
$\mathrm{nmol} \mathrm{MgCl}_{2}, 10 \mathrm{nmol}$ of each $\mathrm{dNTP}$, and $10 \mathrm{pmol}$ of both forward and reverse primer.

\section{MATERIALS AND METHODS}

Media, bacterial isolates, and antibiotics

Isolates and media. The F2, F5, F6, F18, and F19 strains were all Belgian $M$. hyopneumoniae field strains isolated from lung tissue of fattening pigs collected at slaughterhouses. The J strain (ATCC 25934) was used as a control strain. The Friis' broth $^{10}$ without added antibiotics was used to grow the $M$. hyopneumoniae strains.

Antibiotics. Erythromycin, tylosin, and clindamycin were obtained from Sigma (UK). The other antibiotics were obtained from the drug's manufacturer as reference powder: lincomycin and azithromycin were kindly supplied by Pfizer (NY), clarithromycin by Abott (IL).

MIC test by a macro broth dilution technique. Antibiotic stock solutions of $1,000 \mu \mathrm{g} / \mathrm{ml}$ were freshly prepared the day of use according to guidelines described by the National Committee for Clinical Laboratory Standards (NCCLS). ${ }^{22}$ Clarithromycin, erythromycin, and azithromycin were dissolved in a minimum amount of ethanol and further diluted in water. All other antibiotics were directly dissolved in water. For each antimicrobial, two-fold dilutions ranging from $0.015 \mu \mathrm{g} / \mathrm{ml}$ to $64 \mu \mathrm{g} / \mathrm{ml}$ were prepared and each strain was tested twice. Broths were inoculated with the $M$. hyopneumoniae strains, resulting in approximately $10^{5}$ color-changing units (CCU) per $\mathrm{ml}$ in a final volume of $2 \mathrm{ml}$. An additional tube contained only medium and was used as a negative control, while a second tube without antibiotics served as a positive control. The MIC was defined as the lowest concentration of antimicrobial agent in which no growth of $M$. hyopneumoniae was observed. Growth was detected by a color change of the Phenol Red indicator from red to yellow due to glucose fermentation. The test was ended when no more color change in the tubes was visible during 2 consecutive days.

\section{DNA sequencing of the L4- and L22-genes and} domain $V$ of the $23 S$ rDNA

To sequence the L4 and L22 proteins, primers were designed based on the $M$. hyopneumoniae genome sequence of reference strain 232. ${ }^{21}$ Primers for the amplification of domain V of the 23S rDNA were selected based on the M. hyopneumoniae ATCC 27719 strain (GenBank accession number X68421). All primers and reaction conditions used are listed in Table 1. After purification of the PCR product on Microcon 100 columns (Millipore, MA), both strands were sequenced on a CEQ8000

\begin{tabular}{|c|c|c|c|c|c|c|c|}
\hline & 2040 & 2050 & 2060 & 12070 & 12080 & 12090 & 12100 \\
\hline E. $\operatorname{col} i^{a}$ & GTACCCGCGG & CAAGACGGAA & AGACCCCGTG & AACCT'TACT & ATAGCTIGAC & ACTGAACATT & GAGCCTTGATG \\
\hline M. hyopneumoniae & TTACCCGCAT & CAAGACGAAA & AGACCCCGTG & GAGCTTTACT & ATAACTTCGT & ATTGAGAATT & GGTPTATTATG \\
\hline M. hyopneumoniae F19 & TTACCCGCAT & CAAGACGAGA & AGACCCCGTG & GAGCTTTACT & ATAACTTCGT & ATTGAGAATT & GGTTTATTATG \\
\hline M. hominis & AGACCCGCAT & CTAGACGAAA & AGACCCCGTG & GAGCTTTACT & ATAACTTCAT & ATTGGAGTTT & GATTTAACATG \\
\hline M. fermentans & GTACCCGCAT & CAAGACGAAA & AGACCCCATG & GAGCTTTACT & ACAGTTTCGT & ATTGGAACTT & GGTCTAACATG \\
\hline M. genitalium & TTAGGCGCAA & CGGGACGGAA & AGACCCCGTG & AAGCTTTACT & GTAGCTTAAT & ATTGATCAAA & ACACCACCATG \\
\hline M. pneumoniae & TTAGGCGCAA & CGGGACGGAA & AGACCCCGTG & AAGCTTTACT & GTAGCTTAAT & ATTGATCAGG & ACATTATCATG \\
\hline M. gallisepticum & TTAGGCGCAA & CGGGACGGAA & AGACCCCATG & AAGCTTTACT & GTAACTTAAT & ATTGGGCAGA & GTTTAGACATA \\
\hline M. penetrans & TTAGGTGCGG & TTAGACAAAA & AGACCCCATG & AAGCTTTACT & GTAGCTTAAT & ATTGGAAAAA & TTTATTTCATT \\
\hline M. flocculare & TTACCCGCAT & CAAGACGAAA & AGACCCCGTG & GACGTTTACT & ATAACTTCGT & ATTGAGAATT & GGTTTATTATG \\
\hline M. hyorhinis & CGAACCGTAG & TACGCTAAAA & AGTGCCCGGA & TGACTTGTGG & ATAGC $\cdots \cdots$ & GGTGAAATTC & CAATCGA-ACC \\
\hline \multirow[t]{2}{*}{ M. pulmonis } & CGAACCGTAG & TACGCTGAAA & AGTGCCCGGA & TGACTTGTGA & ATAGC----- & GGTGAAATTC & CAATCGA-ACC \\
\hline & * $\quad *$ & * & $* \star \quad * * *$ & $\star \star$ & * & ** & * \\
\hline
\end{tabular}

aSequences were extracted from Genbank. Accession numbers are: Escherichia coli, EC0278710; M. hominis, AF443617; M. fermentans, AF422142; M. genitalium, U39634; M. pneumoniae, AE000007; M. gallisepticum, AE016968; M. penetrans, AP004174; M. flocculare, MYC16SR; M. hyorhinis, AF121891; M. pulmonis, AL445565.

bNo differences in the 23S DNA of strain F2, F5, F6, F18, F23, and J were observed.

${ }^{\mathrm{c}}$ Resistance due to A2062 point mutations have been described elsewhere. ${ }^{10}$

FIG. 1. Multiple sequence alignment of the 23S rDNA of different Mycoplasma spp. compared to E. coli. Nucleotides related to resistance to macrolides are presented in bold. The G2058A transition of the resistant M. hyopneumoniae F19 strain is underlined as well. 
sequencer (Beckmann, UK) according to the manufacturer's instructions. The sequences were aligned for further analysis using Clustal W (V1.82). The sequences of domain V of the $23 \mathrm{~S}$ rDNA of the $M$. hyopneumoniae strains were compared with sequences of E. coli and other Mycoplasma species extracted from GenBank (Fig. 1).

\section{RESULTS}

Because the isolates grew at different rates, not all MICs were read on the same day. The $\mathrm{J}$ reference strain grew faster than the other isolates, and the MICs of the antibiotics were reached after approximately 5 days, whereas it took up to 1 week for the other strains. The MICs for the isolates are presented in Table 2. For each isolate, the MIC values of the replicates were equal to or differed from each other by only one dilution. The MICs for erythromycin and clarithromycin ranged from 8 to $32 \mu \mathrm{g} / \mathrm{ml}$ for all strains tested, except for the resistant F19 isolate. For this strain, the MIC values exceeded the highest concentration $(64 \mu \mathrm{g} / \mathrm{ml})$ tested. All isolates, except the F19 strain, were also susceptible to the other antibiotics tested. The MICs ranged from 0.06 to $0.25 \mu \mathrm{g} / \mathrm{ml}$ for the 15 -membered macrolide, azithromycin; from 0.03 to $0.125 \mu \mathrm{g} / \mathrm{ml}$ for the 16-membered macrolide, tylosin; and from 0.125 to 0.5 $\mu \mathrm{g} / \mathrm{ml}$ for the lincosamides, lincomycin, and clindamycin. The MICs for the resistant isolate (F19) also exceeded the highest concentration of $64 \mu \mathrm{g} / \mathrm{ml}$ for these antibiotics, with the exception of tylosin (MICs ranging from 8 to $16 \mu \mathrm{g} / \mathrm{ml}$ ).

Sequence analysis of the 23S rDNA, as shown in Fig. 1, demonstrates the intrinsic resistance of certain Mycoplasma spp. to 14-membered macrolides due to a G2057A transition. An acquired A2058G transition was found exclusively in the resistant M. hyopneumoniae strain. Only a small number of differences were present in the L22 proteins ( $>97 \%$ identity at DNA level). Protein L4 proved very conserved ( $>99 \%$ identical at DNA level) as no amino acid substitutions were found between any of the strains (data not shown).

\section{DISCUSSION}

Because M. hyopneumoniae strains are difficult to grow on agar plates and colonies are hard to detect, a serial broth dilution technique using Friis' medium was chosen to test for an- tibiotic resistance. This technique, based on an earlier report of Ter Laak et al., ${ }^{34}$ was performed in duplicate and proved to be reproducible.

The J reference strain seemed better adapted to the Friis' medium and grew faster than the other isolates. This may explain the higher MICs, up to one dilution, for this strain. Nevertheless, all individual MICs were very similar for the susceptible strains and clearly differed from those of the resistant F19 strain. Moreover, MICs for the sensitive strains were consistent with previous reports. ${ }^{18,32,34}$

Although $M$. hyopneumoniae strains are naturally resistant to 14-membered macrolides due to a G2057A transition of the 23S gene, ${ }^{36}$ even higher MICs were observed for the resistant strain. This increased resistance may well be explained by the observed A2058G transition because footprinting patterns examining the drug binding sites in other bacteria identified these specific nucleotides. ${ }^{7,17}$ Hence, a lower affinity of the drugs to the $23 \mathrm{~S}$ rRNA, due to the acquired mutation, results in a decreased antimicrobial activity. Apart from this increased insensitivity to erythromycin and clarithromycin, the F19 field isolate proved also resistant to all other antibiotics tested. This is in agreement with earlier reports in other bacterial species where mutations at position 2,058 led to high MLS resistant strains. ${ }^{7,36}$ This A2058G transition may even be the most frequently observed substitution in vivo in association with MLS resistance ${ }^{36}$ and was also found for clinical isolates of M. pneumoniae ${ }^{24}$ although only limited data exist for in vivo-acquired MLS resistance in Mycoplasma species.

Recently, resistance to macrolides and lincosamides has been linked to modifications in the L4 and L22 rRNA-binding proteins, ${ }^{13,23}$ especially in pneumococcal strains. ${ }^{6,9,13,19,23,27,31}$ In the present studies, none of the variations in these proteins was uniquely present in the resistant $M$. hyopneumoniae field isolate F19, and it is therefore unlikely that they are associated with acquired resistance. This is in agreement with an earlier report of resistant clinical strains of M. hominis and M. fermentans. ${ }^{25}$

In in vitro experiments, resistance to tylosin was obtained in M. hyopneumoniae strains after only seven or fewer passages in selective media, ${ }^{15}$ indicating that acquired resistance due to mutations of the 23S RNA may occur quite fast for bacteria like $M$. hyopneumoniae, which only possess one copy of the rRNA operon. ${ }^{30}$ The relation between the use of macrolides in pig rearing and the occurrence of acquired resistance has been indirectly demonstrated for M. hyosynoviae and other porcine

Table 2. MiCs ( $\mu \mathrm{G} / \mathrm{ML}$ ) of MLS-Antimicrobial Agents for Belgian M. hyopneumoniae Field Isolates and the M. hyopneumoniae J Reference Strain Obtained by the Broth Dilution Test Carried Out in Two-Fold

\begin{tabular}{lcccccc}
\hline \multicolumn{7}{c}{ MIC $(\mu \mathrm{g} / \mathrm{ml})$} \\
\cline { 2 - 7 } Strain & Azithromycin & Tylosin & Erythromycin & Clarithromycin & Clindamycin & Lincomycin \\
\hline F2 & $0.125^{\mathrm{a}}$ & 0.03125 & 8 & 16 & 0.0625 & 0.25 \\
F5 & $0.125-0.25$ & 0.03125 & 8 & 16 & $0.125-0.25$ & 0.25 \\
F6 & $0.0625-0.125$ & 0.03125 & 16 & 32 & 0.125 & 0.125 \\
F18 & 0.0625 & 0.0625 & 32 & 32 & $0.125-0.25$ & 0.125 \\
F19 & $>64$ & $8-16$ & $>64$ & 32 & 0.5 & $>64$ \\
J & 0.25 & 0.125 & 32 & 0.5 & 0.5 \\
\hline
\end{tabular}

${ }^{\mathrm{a}}$ One value means that no difference between the repeated tests was observed. 
bacteria. ${ }^{1,2,5}$ In contrast, the prevalence of acquired resistance to macrolides for M. hyopneumoniae in the field is most likely low. ${ }^{18,37}$ It is possible that resistant strains do not spread easily and that occurrence of resistance remains localized in an area or even within a herd. Indeed, earlier RAPD data ${ }^{3}$ and our own PFGE results (unpublished) show an enormous diversity among isolates from different farms, suggesting that clones do not readily spread in the environment, although further research on this issue is needed. Because the type of resistance described above is not encoded on a mobile element, and therefore not transferable between different strains, the genetic stability of the mutation may also be an important factor. Although the A2058G transition has distinct advantages over the wild-type in the presence of macrolides, the situation may be different in the absence of the drugs. ${ }^{36}$ In any event, the emergence of this resistance asks for a continuous monitoring, because it may have important therapeutic implications in the treatment of mycoplasma infections.

\section{ACKNOWLEDGMENTS}

This work was supported by a grant of the Federal Agency of Health, Food Chain Security and Environment (Grant number S-6136). The authors thank Sara Tistaert for skilful technical assistance.

\section{REFERENCES}

1. Aarestrup, F.M., and B. Carstensen. 1998. Effect of tylosin used as a growth promoter on the occurrence of macrolide-resistant enterococci and staphylococci in pigs. Microb. Drug Resist. 4:307-312.

2. Aarestrup, F.M., and N.F. Friis. 1998. Antimicrobial susceptibility testing of Mycoplasma hyosynoviae isolated from pigs during 1968 to 1971 and during 1995 and 1996. Vet. Microbiol. 61:33-39.

3. Artiushin, S., and F.C. Minion. 1996. Arbitrarily primed PCR analysis of Mycoplasma hyopneumoniae field isolates demonstrates genetic heterogeneity. Int. J. Syst. Bacteriol. 46:324-328.

4. Berisio, R., J. Harms, F. Schluenzen, R. Zarivach, H.A. Hansen, P. Fucini, and A. Yonath. 2003. Structural insight into the antibiotic action of telithromycin against resistant mutants. J. Bacteriol. 185:4276-4279.

5. Butaye, P., L.A. Devriese, and F. Haesebrouck. 2001. Differences in antibiotic resistance patterns of Enterococcus faecalis and Enterococcus faecium strains isolated from farm and pet animals. Antimicrob. Agents Chemother. 45:1374-1378.

6. Canu, A., B. Malbruny, M. Coquemont, T.A. Davies, P.C. Appelbaum, and R. Leclercq. 2002. Diversity of ribosomal mutations conferring resistance to macrolides, clindamycin, streptogramin, and telithromycin in Streptococcus pneumoniae. Antimicrob. Agents Chemother. 46:125-131.

7. Edelstein, P.H. 2004. Pneumococcal resistance to macrolides, lincosamides, ketolides, and streptogramin B agents: molecular mechanisms and resistance phenotypes. Clin. Infect. Dis. (Suppl). 38:S322-S327.

8. Farrell, D.J., I. Morrissey, S. Bakker, S. Buckridge, and D. Felmingham. 2004. In vitro activities of telithromycin, linezolid, and quinupristin-dalfopristin against Streptococcus pneumoniae with macrolide resistance due to ribosomal mutations. Antimicrob. Agents Chemother. 48:3169-3171.
9. Franceschi, F., Z. Kanyo, E.C. Sherer, and J. Sutcliffe. 2004. Macrolide resistance from the ribosome perspective. $\underline{\text { Curr. Drug }}$ Targets Infect. Disord. 4:177-91.

10. Friis, N.F. 1975. Some recommendations concerning primary isolation of Mycoplasma suipneumoniae and Mycoplasma flocculare a survey. Nord. Vet. Med. 27: 337-339.

11. Furneri, P.M., G. Rappazzo, M.P. Musumarra, P. Di Pietro, L.S. Catania, and L.S. Roccasalva. 2001. Two new point mutations at A2062 associated with resistance to 16-membered macrolide antibiotics in mutant strains of Mycoplasma hominis. Antimicrob. Agents Chemother. 45:2958-2960.

12. Furneri, P.M., G. Rappazzo, M.P. Musumarra, G. Tempera, and L.S. Roccasalva. 2000. Genetic basis of natural resistance to erythromycin in Mycoplasma hominis. J. Antimicrob. Chemother. 45:547-548.

13. Gabashvili, I. S., S.T. Gregory, M. Valle, R. Grassucci, M. Worbs, M.C. Wahl, A.E. Dahlberg, and J. Frank. 2001. The polypeptide tunnel system in the ribosome and its gating in erythromycin resistance mutants of L4 and L22. Mol. Cell. 8:181-188.

14. Garza-Ramos, G., L. Xiong, P. Zhong, and A. Mankin. 2001. Binding site of macrolide antibiotics on the ribosome: new resistance mutation identifies a specific interaction of ketolides with rRNA. J. Bacteriol. 183:6898-6907.

15. Hannan, PC., H.M. Windsor, and P.H. Ripley. 1997. In vitro susceptibilities of recent field isolates of Mycoplasma hyopneumoniae and Mycoplasma hyosynoviae to valnemulin (Econor), tiamulin and enrofloxacin and the in vitro development of resistance to certain antimicrobial agents in Mycoplasma hyopneumoniae. Res. Vet. Sci. 63:157-160.

16. Hansen, J.L., J.A. Ippolito, N. Ban, P. Nissen, P.B. Moore, and T.A. Steitz. 2002. The structures of four macrolide antibiotics bound to the large ribosomal subunit. Mol. Cell. 10:117-128.

17. Hansen, L.H., P. Mauvais, and S. Douthwaite. 1999. The macrolide-ketolide antibiotic binding site is formed by structures in domains II and V of $23 \mathrm{~S}$ ribosomal RNA. Mol. Microbiol. 31:623-631.

18. Inamoto, T., H. Takahashi, K. Yamamoto, Y. Nakai, and K. Ogimoto. 1994. Antibiotic susceptibility of Mycoplasma hyopneumoniae isolated from swine. J. Vet. Med. Sci. 56:393-394.

19. Jones, RN., D.J. Farrell, and I. Morrissey. 2003. Quinupristindalfopristin resistance in Streptococcus pneumoniae: novel L22 ribosomal protein mutation in two clinical isolates from the SENTRY antimicrobial surveillance program. Antimicrob. Agents Chemother. 47:2696-2698.

20. Ludwig, W., G. Kirchhof, N. Klgubauer, M. Weizenegger, D. Betzl, M. Ehrmann, C. Hertel, S. Jilg, R. Tatzel, H. Zitzelsberger, S. Liebl, M. Hochberger, J. Shah, D. Lane, P.R. Wallnöfer, and K.H. Scheifer. 1992. Complete 23S ribosomal RNA sequences of Gram-positve bacteria with a low DNA G+C content. System. Appl. Microbiol. 15:487-501.

21. Minion, F.C., E.J. Lefkowitz, M.L. Madsen, B.J. Cleary, S.M. Swartzell, and G.G. Mahairas. 2004. The genome sequence of Mycoplasma hyopneumoniae strain 232, the agent of swine mycoplasmosis. J. Bacteriol. 186:7123-7133.

22. NCCLS. 1999. Performance standards for antimicrobial disk and dilution susceptibility tests for bacteria from animals. Approved standard M31-A. National Committee for Clinical Laboratory Standards, Pennsylvania, Wayne, PA, pp. 1-64.

23. O'Connor, M., S.T. Gregory, and A.E. Dahlberg. 2004. Multiple defects in translation associated with altered ribosomal protein L4. Nucleic Acids Res. 32:5750-5756.

24. Okazaki, N., M. Narita, S. Yamada, K. Izumikawa, M. Umetsu, T. Kenri, Y. Sasaki, Y. Arakawa, and T. Sasaki. 2001. Characteristics of macrolide-resistant Mycoplasma pneumoniae strains isolated from patients and induced with erythromycin in vitro. Microbiol. Immunol. 45:617-620. 
25. Pereyre, S., P. Gonzalez, B. De Barbeyrac, A. Darnige, H. Renaudin, A. Charron, S. Raherison, C. Bebear, and C.M. Bebear. 2002. Mutations in 23S rRNA account for intrinsic resistance to macrolides in Mycoplasma hominis and Mycoplasma fermentans and for acquired resistance to macrolides in M. hominis. Antimicrob. Agents Chemother. 46:3142-3150.

26. Pereyre, S., C. Guyot, H. Renaudin, A. Charron, C. Bebear, and C.M. Bebear. 2004. In vitro selection and characterization of resistance to macrolides and related antibiotics in Mycoplasma pneumoniae. Antimicrob. Agents Chemother. 48:460-465.

27. Pihlajamaki, M., J. Kataja, H. Seppala, J. Elliot, M. Leinonen, P. Huovinen, and J. Jalava. 2002. Ribosomal mutations in Streptococcus pneumoniae clinical isolates. Antimicrob. Agents Chemother. 46:654-658.

28. Retsema, J., and W. Fu. 2001. Macrolides: structures and microbial targets. Int. J. Antimicrob. Agents(Suppl).18:S3-S10.

29. Schlünzen, F., J.M. Harms, F. Franceschi, H.A. Hansen, H. Bartels, R. Zarivach, and A. Yonath. 2003. Structural basis for the antibiotic activity of ketolides and azalides. Structure (Camb). 11:329-338.

30. Stemke, G.W., Y. Huang, F. Laigret, and J.M. Bove. 1994. Cloning the ribosomal RNA operons of Mycoplasma flocculare and comparison with those of Mycoplasma hyopneumoniae. Microbiology. 140:857-860.

31. Tait-Kamradt, A., T. Davies, M. Cronan, M.R. Jacobs, P.C. Appelbaum, and J. Sutcliffe. 2000. Mutations in 23S rRNA and ribosomal protein L4 account for resistance in pneumococcal strains selected in vitro by macrolide passage. Antimicrob. Agents Chemother. 44:2118-2125.

32. Tanner, A.C., B.Z. Erickson, and R.F. Ross. 1993. Adaptation of the Sensititre broth microdilution technique to antimicrobial sus- ceptibility testing of Mycoplasma hyopneumoniae. Vet. Microbiol. 36:301-306.

33. Tenson, T., M. Lovmar, and M. Ehrenberg. 2003. The mechanism of action of macrolides, lincosamides and streptogramin B reveals the nascent peptide exit path in the ribosome. J. Mol. Biol. 330:1005-1014.

34. Ter Laak, E.A., A. Pijpers, J.H. Noordergraaf, E.C. Schoevers, and J.H. Verheijden. 1991. Comparison of methods for in vitro testing of susceptibility of porcine Mycoplasma species to antimicrobial agents. Antimicrob. Agents Chemother. 35:228233.

35. Thomas, A., C. Nicolas, I. Dizier, J. Mainil, and A. Linden. 2003. Antibiotic susceptibilities of recent isolates of Mycoplasma bovis in Belgium. Vet. Rec. 153:428-431.

36. Vester, B., and S. Douthwaite. 2001. Macrolide resistance conferred by base substitutions in $23 \mathrm{~S}$ rRNA. Antimicrob. Agents Chemother. 45:1-12.

37. Vicca, J., T. Stakenborg, D. Maes, P. Butaye, J. Peeters, A. de Kruif, and F. Haesebrouck. 2004. In vitro susceptibilities of Mycoplasma hyopneumoniae field isolates. Antimicrob. Agents Chemother. 48:4470-4472.

Address reprint requests:

Dr. Tim Stakenborg Veterinary and Agrochemical Research Centre Groeselenberg 99 1180 Brussels, Belgium

E-mail: tista@var.fgov.be 


\section{This article has been cited by:}

1. Satu Pyörälä, Keith Edward Baptiste, Boudewijn Catry, Engeline van Duijkeren, Christina Greko, Miguel A. Moreno, M. Constança Matias Ferreira Pomba, Merja Rantala, Modestas Ružauskas, Pascal Sanders, E. John Threlfall, Jordi Torren-Edo, Karolina Törneke. 2014. Macrolides and lincosamides in cattle and pigs: Use and development of antimicrobial resistance. The Veterinary Journal 200, 230-239. [CrossRef]

2. Uri Lerner, Eytan Amram, Roger D. Ayling, Inna Mikula, Irena Gerchman, Shimon Harrus, Dina Teff, David Yogev, Inna Lysnyansky. 2013. Acquired resistance to the 16-membered macrolides tylosin and tilmicosin by Mycoplasma bovis. Veterinary Microbiology . [CrossRef]

3. Irena Gerchman, Sharon Levisohn, Inna Mikula, Lucia Manso-Silvan, Inna Lysnyansky. 2011. Characterization of in vivoacquired resistance to macrolides of Mycoplasma gallisepticum strains isolated from poultry. Veterinary Research 42, 90. [CrossRef]

4. Ania T. Deutscher, Cheryl Jenkins, F. Chris Minion, Lisa M. Seymour, Matthew P. Padula, Nicholas E. Dixon, Mark J. Walker, Steven P. Djordjevic. 2010. Repeat regions R1 and R2 in the P97 paralogue Mhp271 of Mycoplasma hyopneumoniae bind heparin, fibronectin and porcine cilia. Molecular Microbiology 78:10.1111/mmi.2010.78.issue-2, 444-458. [CrossRef]

5. P. Assunção, N.T. Antunes, R.S. Rosales, C. Poveda, C. de la Fe, J.B. Poveda, H.M. Davey. 2006. Application of flow cytometry for the determination of minimal inhibitory concentration of several antibacterial agents on Mycoplasma hyopneumoniae. Journal of Applied Microbiology 0:10.1111/jam.0.0.issue-0, 061120055200048-???. [CrossRef] 